\title{
RESENHAS
}

\section{TEORIA FEMINISTA: DA MARGEM AO CENTRO}

\section{Sara Cristina Martins da Silva ${ }^{1}$}

O livro "Teoria feminista - da margem ao centro", escrito pela ativista norte americana bell hooks em 1952 e publicado no Brasil em 2019, tem ênfase na interseccionalidade da luta feminista, através de uma série de reflexões sobre questões de raça, classe e sexualidade, traz luz a necessidade e propõem caminhos para construir um movimento feminista verdadeiramente inclusivo e revolucionário.

A autora, enquanto mulher negra ativista dos movimentos sobre gênero e raça de meados do século XX, assegura que nos EUA, o movimento feminista jamais foi protagonizado por mulheres negras. Isso causou por muito tempo uma narrativa totalmente centrada na realidade vivida por mulheres brancas e ricas que detinham uma série de privilégios sociais, mas que estavam condenadas ao confinamento doméstico.

A estrutura social estadunidense foi moldada de acordo com a supremacia branca, isso afetou diretamente o movimento feminista da época, que subestimava a hierarquização racial como modos operandi da realidade capitalista e sexista. Um dos pressupostos do feminismo naquele tempo era a ideia de que todas as mulheres eram igualmente oprimidas, no entanto, isso desconsiderava uma seria de peculiaridades que atravessavam a vida de mulheres negras e operárias no interior de uma sociedade desigual.

A autora nos traz que a opressão pressupõe a falta de opção e isso por vezes não era o que acontecia em relações sexistas. Mulheres podiam fazer escolhas (boas ou más), assim, termos como discriminação ou exploração, descreveriam melhor a realidade comum da mulher estadunidense. A sustentação de uma opressão comum, segundo hooks,

\footnotetext{
${ }^{1}$ Mestranda em Política Social pela Universidade Federal de Mato Grosso (PPGPS/UFMT). Graduada em Direito pela Universidade do Estado de Mato Grosso (UNEMAT). Membro do Núcleo de Estudos e Pesquisa Sobre a Organização da Mulher e Relações de Gênero (NUEPOM/UFMT). saracristinamartins96@gmail.com.
} 
foi mais uma estratégia para manipular o movimento feminista, dentro de uma narrativa única, focando sempre na promoção dos interesses de mulheres privilegiadas que ignoravam as desigualdades existentes entre elas e a maioria da população feminina trabalhadora.

Por essa razão o movimento feminista dos EUA era frequentemente cooptado pelos interesses de forças conservadoras e liberais, fazendo do feminismo uma ideologia burguesa. Para resistir a essa cooptação, seria preciso, antes de tudo, construir uma perspectiva feminista diferente - uma nova teoria -, cujo pressuposto não fosse a ideologia do individualismo liberal.

Estereótipos racistas maculam as relações entre feministas brancas e negras. bell hooks aponta que sua inserção dentro de grupos feministas fora marcada de hostilidade por parte de feministas brancas. Essa hostilidade seria usada para lembrá-la que o movimento pertenciam a elas - mulheres brancas, e que a presença de mulheres negras, independentemente de seu grau de instrução, seria tolerada apenas se acompanhada de uma postura de subalternidade intelectual, que delegava as feministas brancas a decisão sobre a autenticidade das experiencias vividas por mulheres negras. Em geral, esperava que a participação de mulheres negras fosse dentro do estereótipo que a autora chama de "verdadeira" negritude, ou seja, "dialetos de negros e pobres, baixa instrução e um comportamento de quem nasceu nas ruas". A mulher negra seria ouvida apenas se sua fala ecoasse de acordo com estereótipos racistas do que se esperava de uma pessoa negra e pobre.

Não se pode olvidar que mulheres negras ocupavam e ainda ocupam uma posição singular dentro da esfera hierárquica da sociedade ocidental, segundo hooks, para a mulher negra não existe "outro" institucionalizado como objeto de exploração, isso porquê, carregam o fardo da opressão sexista, racista e classista sobre si. Justamente por isso era necessária uma abordagem feminista que desse enfoque a questão racial como um determinante da opressão feminina, de uma práxis feminista crítica libertadora, de responsabilidade de todos.

Prosseguindo nas críticas ao feminismo de sua época, a autora reflete sobre as definições do que significa feminismo e do que se pretende com ele. Para a maioria, o movimento feminista tinha a intenção de tornar as mulheres socialmente iguais aos 
homens. Todavia, essa definição genérica, mais uma vez, não abarcava a interferência racial sobre o feminino. A autora questiona, se os homens não eram iguais entre si dentro de uma estrutura patriarcal e supremacista branca, com quais homens, as mulheres queriam se igualar? Mulheres pobres, em sua maioria não brancas, não queriam se igualar ao homem de seu grupo social, pois eram continuamente lembradas de que nem todas as mulheres partilhavam entre si dos mesmos status socais. E para uma mulher negra se igualar a um homem negro, não significaria libertação.

A autora então, discorre uma crítica às feministas liberais, que discursavam por reformas radicais na sociedade patriarcal, porém, que jamais iriam ocorrer, pois caso fossem implantadas lançariam as bases para uma transformação revolucionária que não era concebida dentro de uma narrativa liberal. E mais, era justamente a superficialidade das propostas do feminismo liberal, que o tornava atrativo a sociedade, pois não apresentavam risco real ao status quo, reforçavam o capitalismo e seus valores materiais, sem emancipar todas mulheres em termos econômicos.

A maioria das definições de feminismo soavam para hooks, desprovidas de significado claro, eram sem critérios, pelo fato de que qualquer mulher que desejasse igualdade de gênero, independentemente de sua perspectiva política (conservadora de direita ou comunista nacionalista) poderia se apresentar como feminista. E em sua maioria as definições do que era feminismo diziam respeito aos direitos à liberdade e a autodeterminação, assumindo assim, um caráter liberal.

Outra questão marcante da obra é o papel desempenhado pela família clássica na manutenção das opressões. Argumenta que a opressão sexista seria a primazia das opressões, pois é a base de outras opressões, como também, a que atinge a maior parte das pessoas. É a pratica opressora que a grande parte das pessoas aprendem a aceitar experimentada no âmbito familiar - antes de saber que existem outras formas de opressão - se referindo as opressões de raça e classe, experimentadas fora de casa. No entanto, a eliminação do sexismo apenas, não resultaria na erradicaria todas as outras formas de opressão.

Uma vez que a o sexismo é a forma primária de opressão, a família, em termos clássicos, é a responsável por transmitir valores dualistas hierárquicos e de controle 
coercitivo, sendo em muitas sociedades a mais importante estrutura social de pertencimento.

Dentro de uma estrutura de opressão sexista patriarcal, experimentada pela maioria dos indivíduos dentro dos lares, aprendemos a aceitar a opressão sexista como natural e somos preparados para suportar outras opressões em meio social mais amplo, como as opressões de raça e classe. Assim, a luta pelo fim da opressão sexual, fortalece outras lutas por libertação.

No que se refere a solidariedade entre homens e mulheres e brancas e negras. Mulheres negras, pobres e/ou não brancas, em geral, possuíam maior identificação com homens do mesmo grupo racial e/ou de mesma classe, do que com mulheres burguesas. Isso representou um afastamento de mulheres de classes operárias dos discursos feministas "anti-homem". Pois, mulheres negras e pobres, vivenciavam sua luta e existência ao lado desses homens negros, pobres, em detrimento de mulheres brancas, que, inclusive, as oprimiam. A autora aponta, que na luta pelo fim do racismo, as mulheres negras estadunidense tiveram a mesma relevância e equivalência que os homens negros.

Foi essa equivalência que fez com que a mulher negra rejeitasse o rótulo "antihomem" e relutasse em adentrar o movimento feminista. Em geral, as mulheres burguesas não entendiam o elo da luta pela libertação racial existente entre a mulher e o homem negro, pois nunca vivenciou tal luta numa perspectiva branca.

O homem, reproduzindo a opressão sexista, é, ao mesmo tempo, opressor e oprimido e essa dualidade é especialmente experimentada dentro da comunidade negra, onde o homem, oprime - reproduzindo o patriarcado -, como também é oprimido relações de classe/raça. Assim, subestimar as reais necessidades pelas quais mulheres se relacionam com homens, seria um desgaste desnecessário para aquelas que desejam o feminismo.

Outro ponto trazido pela autora, é a relação da mulher com o poder. A crença de que a mulher, assim que tivesse acesso ao poder, livre das opressões de gênero, o desenvolveria de modo distinto dos homens, ou seja, que não se baseasse em dominação e exploração, é um equívoco. Isso porque, homens e mulher são criados numa mesma sociedade e compartilham de um mesmo sistema de valores. Deste modo, a abordagem 
mistificada de que mulheres são diferentes de homens, uma vez que elas são vítimas e eles inimigos torna a discurso demasiado simplista.

Exemplo dessa reprodução de estruturas de poder entre homens e mulheres seria a persistência do racismo dentro do movimento feminista. Mulheres negras e operarias nunca foram modelo para uma práxis feminista branca, onde mulheres burguesas exerciam seu poder do mesmo modo que os homens.

A dominação do homem sobre a mulher deve ser entendida sobre a perspectiva do capitalismo. Para hooks, pela dominação econômica do capitalismo, foi retirado do homem seu controle e autoridade sobre a família e sobre a comunidade, em substituição, os homens fantasiam relações de poder e controle, que outrora tinham, e esperam que no mundo privado haja a reparação de seu senso de poder, que equiparam a masculinidade, gerando assim a violência doméstica. A inserção da mulher ao mercado de trabalho, roubou ainda mais o controle dos homens sobre as mulheres, tornando-os ainda mais dependentes do usa da violência para estabelecer e manter a hierarquia de outrora, que os beneficia enquanto dominantes.

Esse ciclo se intensifica quando se trata de homens e mulheres negros. A dependência econômica do homem ao capital, o obriga a suportar humilhação e degradação. No ambiente de trabalho, esse homem reprime a violência, mas a alivia no ambiente familiar. Para quebrar esse ciclo de violência, homens e mulheres precisam criticar a noção sexista de masculinidade e compreender o impacto do capitalismo em suas vidas.

Quanto à opressão sexual, a autora ressalta a necessidade de se combater lógicas binárias de sexualidade (heterossexualidade e homossexualidade) que impedem dimensões múltiplas de desejo sexual, ressaltando que o movimento feminista tende a transforma a luta contra a opressão sexual em uma competição entre heterossexualidade e lesbianismo, reforçando padrões sexuais pelos quais mulheres são medidas e julgadas. Não deixando de ressaltar que no movimento feminista, as mulheres lésbicas foram as grandes responsáveis por chamar a atenção para a luta contra a opressão heterossexista e capitanearam o debate a respeito da libertação sexual para todas as mulheres.

Para por fim a opressão sexual, são necessárias condições sociais em que LGBT's não sejam mais oprimidos, e todas as orientações sexuais sejam afirmadas. De mesmo 
modo, a heterossexualidade precisa ser exercida sem ser contaminada com o heterossexismo. Assim, uma práxis feminista de sexualidade desassociada das noções socialmente construídas nos moldes e formatos da dominação masculina, da heterossexualidade compulsória, da frustração sexual e do consumismo, são caminhos para erradicar a opressão sexual e fazer uma revolução social.

Finalmente, bell hooks sem esquecer as dimensões positivas do movimento feminista até então, pontua a importância de criticar e reorganizar o movimento feminista para que, através dele, se efetive mudanças revolucionárias. A intenção da autora é construir um feminismo de massa que acolha todas as mulheres, tanto aquelas das margens quanto do centro, remodelar as relações com os homens, aceitá-los como aliados fundamentais para reestabelecer planos de ações teóricos e práticos, a fim de transformar a realidade e suas variadas formas de opressão.

\section{Referência}

HOOKS, bell. Teoria feminista: da margem ao centro. São Paulo: Perspectiva, 2019.

Recebido em: 20/12/2020

Aceito em: 12/01/2021 